\title{
Meta-Analysis
}

Neonatology

\section{Zinc Supplementation and the Prevention and Treatment of Sepsis in Young Infants: A Systematic Review and Meta-Analysis}

\author{
Omar Irfan ${ }^{a}$ Robert E. Black ${ }^{b}$ Zohra S. Lassic Zulfiqar A. Bhutta ${ }^{a, d}$ \\ aCentre for Global Child Health, The Hospital for Sick Children, Toronto, ON, Canada; bepartment Global Disease \\ Epidemiology and Control, Baltimore, MD, USA; 'Robinson Research Institute, Adelaide Medical School, The

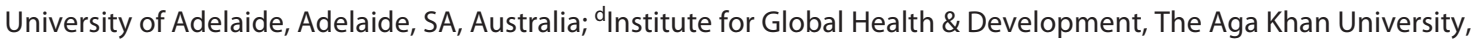 \\ Karachi, Pakistan
}

\section{Keywords}

Zinc · Neonatal sepsis · Young infant sepsis · Treatment ·

Efficacy $\cdot$ Mortality

\begin{abstract}
Background: Prematurity and low birth weight are major risk factors for neonatal sepsis. Zinc supplements have been previously shown to be beneficial in pregnancy and small for gestational age birth outcomes. There is sparse information, however, on the potential benefits of zinc supplementation to prevent or treat serious infections in this age group. $\mathbf{O b}$ jective: The aim of this study was to assess the efficacy of preventive and therapeutic zinc supplementation in young infant ( $<4$ months) sepsis. Methods: MEDLINE, Cochrane CENTRAL, and other databases were searched from inception until 18 June 2021. Studies assessing preventive and therapeutic zinc supplementation in young infants in relation to incidence and outcomes of suspected sepsis were included. Meta-analyses of pooled effects were calculated for sepsis-related outcomes. Results: Nine randomized controlled trials involving 2,553 infants were included. Six studies reported therapeutic efficacy, whereas 3 evaluated preventive benefits of zinc supplementation. Preventive studies suggest a protective effect of zinc supplementation on neonatal mortality rate (NMR) (risk ratio (RR) $0.28 ; 95 \%$ Cl $0.12-$
\end{abstract}

0.67 , LOW certainty), but with no effect on the incidence of sepsis, both in preterm neonates. Among young infants, therapeutic zinc was associated with significant reductions in treatment failure (RR $0.61 ; 95 \% \mathrm{Cl} 0.44-0.85$; MODERATE certainty) and further subgroup analysis showing significant reduction in infant mortality rate with $3 \mathrm{mg} / \mathrm{kg} /$ twice a day dosage only (RR $0.49 ; 95 \% \mathrm{Cl} 0.27-0.87$, LOW certainty). Therapeutic zinc supplementation in neonates did not show any effect on hospital stay or NMR. Conclusion: Zinc supplementation could potentially reduce mortality and treatment failure in young infants but has no noteworthy influence on hospital stay and in the prevention of sepsis. Further studies with larger sample sizes are needed to confirm the direction and magnitude of effects if any. @ 2022 The Author(s)

Published by S. Karger AG, Basel

\section{Introduction}

Sepsis is among the leading causes of morbidity and mortality among newborns and young infants [1]. In 2017, almost half of all the worldwide cases of sepsis occurred in children, with an estimated 20 million cases and 2.9 million deaths in children under five [2]. The incidence of neonatal sepsis is estimated to be between 1 and 12 per 1,000 live births in high-income countries with up to 38 per 1,000 live karger@karger.com www.karger.com/neo

Karger $\stackrel{\text { ' }}{5}$

BOPEN ACCESS
C 2022 The Author(s)

Published by S. Karger AG, Basel

This is an Open Access article licensed under the Creative Commons Attribution-NonCommercial-4.0 International License (CC BY-NC) (http://www.karger.com/Services/OpenAccessLicense), applicable to the online version of the article only. Usage and distribution for commercial purposes requires written permission.
Correspondence to:

Zulfiqar A. Bhutta, zulfiqar.bhutta@ sickkids.ca 
births in low- and middle-income countries (LMICs) [3]. Neonatal sepsis may be divided into early-onset sepsis (EOS) and late-onset sepsis based on the time of onset. EOS is usually acquired vertically from a colonized mother, while the infection in late-onset sepsis is usually acquired from the community or in the hospital setting. Prematurity and low birth weight are major risk factors for neonatal sepsis [4]. The risk factors for EOS include maternal intrapartum infection, multiple gestations, prolonged labor, preterm rupture of the membrane, and meconium aspiration syndrome [5]. Late-onset sepsis also has several risk factors such as mechanical ventilation, hospital stay, prolonged parenteral nutrition, intravascular catheterization, and underlying respiratory or cardiovascular diseases [6]. Evidence has shown early initiation of antibiotic therapy in neonates with suspected sepsis to reduce both mortality and morbidity [3]. Beta-lactams (e.g., penicillins, cephalosporins, monobactams, and carbapenems), aminoglycosides (e.g., gentamycin), and glycopeptides (e.g., vancomycin and teicoplanin) are the most common types of antibiotics used for treating neonatal sepsis [7].

Approximately $85.0 \%$ of the sepsis-related morbidity and mortality globally occurred in the LMICs [2], where interventions, especially those that are low-cost and can be made widely available in low-resource settings are urgently needed. Zinc, which has been labeled as a cost-effective intervention by the World Health Organization in the form of supplementation and fortification [8], is an important micronutrient with roles in immunity, growth, and reproduction [9]. Zinc has a proven role in immunity, growth, cognition, and motor function. Zinc modulates T-cell function and the adaptive immune system with anti-oxidant and anti-inflammatory functions [10]. Zinc has proven effectiveness to address childhood pneumonia and diarrhea, the 2 most common childhood infections worldwide [11]. In order to ensure an adequate concentration of zinc in newborns, it is imperative to target maternal nutrition. Lower maternal zinc status has been linked with low birth weight, fetal loss, fetal growth retardation, and preterm deliveries [12]. Lower plasma zinc levels could reduce placental zinc transport and therefore a lower fetal zinc supply. United Nations Children's Fund (UNICEF) recommends the use of multiple micronutrient supplements including zinc by all pregnant women in developing countries [13]. World Health Organization, in addition to oral rehydration and feeding, further recommends 10-14 days' regimen of zinc supplementation for every episode of childhood diarrhea [14]. However, the role of zinc in the treatment of diarrhea in young infants under 6 months of age is uncertain as past studies among breastfed infants under 6 months of age failed to show any benefit. However, other outcomes such as serious infections have been poorly studied [15].

Higher concentrations of serum zinc have been shown to be associated with improved immunity and prognosis in neonatal sepsis [16]. We undertook a systematic review to determine the efficacy and safety of preventive and therapeutic zinc supplementation in reducing morbidity and mortality of clinical or blood culture-proven sepsis in newborns and young infants (the first 4 months after birth). There have been inconsistent conclusions on the benefits of zinc supplementation in neonates from controlled trials and systematic reviews on mortality and morbidity related to sepsis [17-21]. The review by Tang et al. [17] reported effect estimates from overlapping participants in multiple studies from a single site, leading to potentially inaccurate effect estimation [43]. This review includes both neonates and young infants $(<4$ months of age) in evaluating the effectiveness of zinc intervention in sepsis. This review will potentially inform policymakers and practitioners in improving the outcomes of sepsis in this high-risk population group.

\section{Methods}

This systematic review is reported according to the Preferred Reporting Items for Systematic Reviews and Meta-analysis (PRISMA) and a PRISMA checklist has been provided as online supplementary file (see www.karger.com/doi/10.1159/000521275 for all online suppl. material) to ensure conformity to PRISMA guidelines. The protocol of the review is registered with PROSPERO CRD42021235626.

\section{Objectives}

This review will address the following research objectives:

1. Assess the effectiveness and safety of preventive and therapeutic oral zinc supplementation versus no intervention or placebo in neonatal and young infant sepsis

2. Determine subgroups of neonates and young infants who would benefit more from zinc supplementation

3. Determine the optimal dose and duration of zinc supplementation in this population

\section{Search and Selection Criteria}

A comprehensive search of MEDLINE, Cochrane Controlled Trials Register (CENTRAL), Embase, CINAHL, SCOPUS, Web of Science, Latin American and Caribbean Health Sciences Literature (LILACS), Google Scholar, and ClinicalTrials.gov databases covering timeline from inception to 18 June 2021 was conducted. No restrictions were applied for country, ethnicity, sex, or language. Efforts were made to contact the relevant authors for the identification of unpublished and ongoing studies. References sections and annotated bibliographies of included studies were cross-referenced for additional eligible studies. 


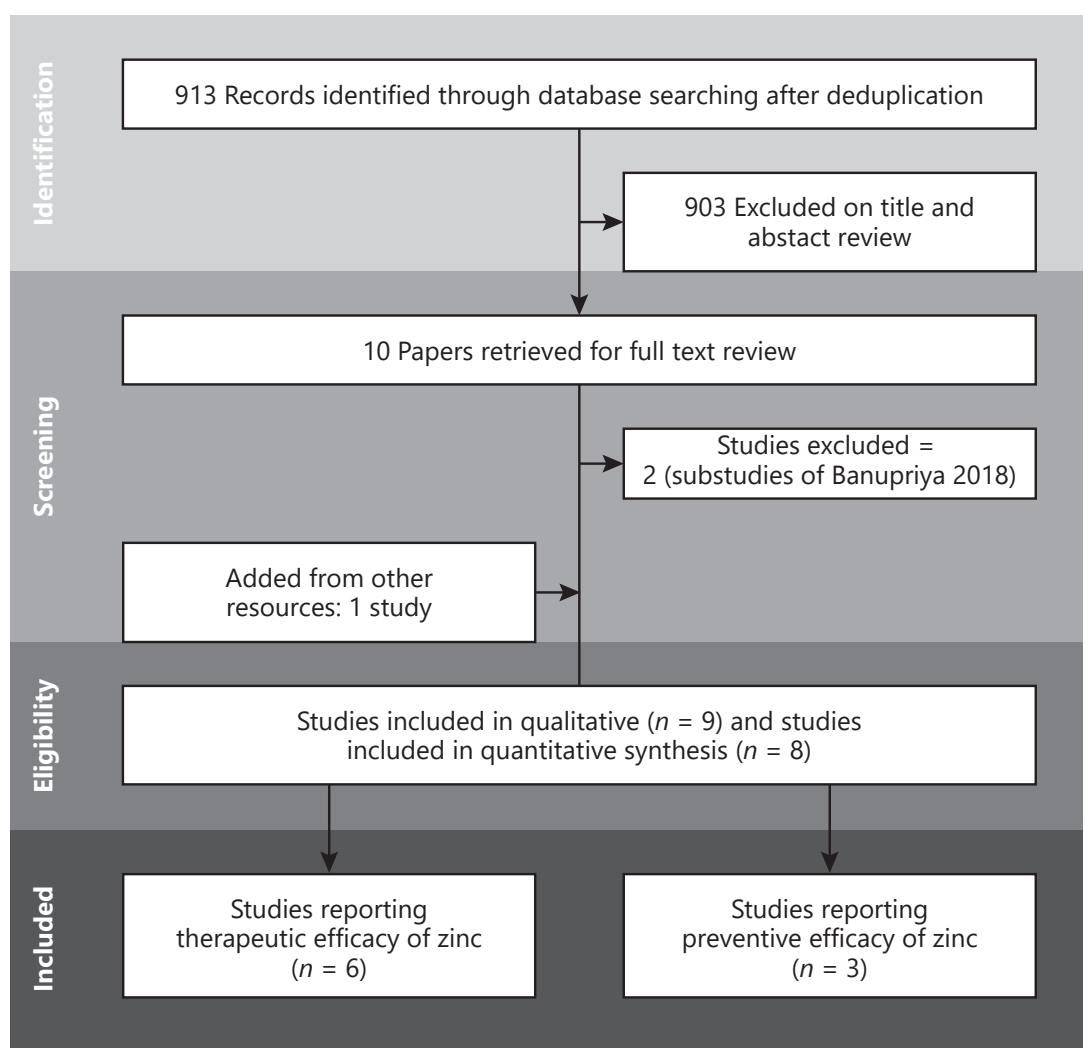

Fig. 1. Flow diagram of the systematic review process.

A search strategy was formulated as below:

1. zinc $[$ mesh] or zinc.tw.

2. infant, newborn [mesh] or neonate.tw or infant.tw or infant, premature[mesh].

3. sepsis[mesh] or sepsis.tw or neonatal sepsis[mesh] or infection. tw or infections[mesh].

4. \#1 AND \#2 AND \#3.

\section{Eligibility Criteria}

We included randomized controlled trials (RCTs). Nonrandomized and observational studies were excluded. The target population of the review was young infants ( $<4$ months). We excluded patients older than 4 months. There was no restriction applied for birth weight, gestational ages, and underlying comorbidities. This review focused on oral zinc supplementation in any form and dose in addition to standard care. Trials with additional micro-/macronutrient or antibiotics were considered if they were given equally in both intervention and placebo groups.

\section{Types of Outcome Measures}

Primary Outcomes

- All-cause Mortality rate (events/total)

- Hospital admission (events/total) and stay duration (hours or days)
- Intensive care unit (ICU) admission (events/total) and stay duration (hours or days)

- Treatment failure (events/total), defined as worsening or persistence of clinical features, change in the antibiotic treatment regimen, requirement of intensive care, or death

- Incidence of sepsis in prevention studies (events/total)

Secondary Outcomes

- Incidence of other diseases as reported by study authors (events/total)

- Serum zinc concentrations (mg/L)

Data Extraction (Selection and Coding) and Analysis

Studies retrieved using the search strategy were entered into Covidence Systematic Review Software (Veritas Health Innovation 2016, Melbourne, SA, Australia) for screening. All titles and abstracts were screened against the aforementioned inclusion criteria in duplicate by 2 authors. Any conflicts were settled by an independent third author. This was followed by a full-text screening. The following data were extracted from each study using standardized data abstraction form: author names, date of publication, study design, city, country, sample size, sex (male/female), patient comorbidities, birth details, zinc supplementation details, control arm details, mortality rate, serum zinc concentrations, the incidence of sepsis and other diseases as reported, treatment failure, hospital/ICU admission, and days of stay. 
Table 1. Characteristics of included studies $(n=9)$

\begin{tabular}{lll}
\hline $\begin{array}{l}\text { Study name } \\
\text { and Year }\end{array}$ & Study setting, City, Participants & Interventions Outcomes
\end{tabular}

Therapeutic Zinc supplementation studies

Banupriya N, NICU of a hospital, 150 Neonates $<28$ days,

$2018 \quad$ Pondicherry, India gestational age of babies $\geq 32$ weeks, on significant enteral feeds with diagnosis of sepsis.

Substudy:

Banupriya N,

2017

134 Neonates
Zinc sulfate dry syrup formulation was administered orally to the babies in zinc group in a dose of $3 \mathrm{mg} / \mathrm{kg}$ twice a day for 10 days. Antibiotics and supportive care were given to the neonates in both groups.

Substudy:

Newton B, 2016
88 Neonates
Expired patients; zinc 5/75 and control $13 / 75$, serum zinc; zinc $870.6 \pm 230.7$ and control $795.31 \pm 207.5$, hospital stay; zinc 15 (10-45) and control 15 (11-46). The Motor Developmental Quotient (MoDQ) was $81.8 \pm 18.24$ and $83.24 \pm 16.64$ ( $p=$ 0.67 ) in "no zinc" and "zinc" group respectively. The Mental Developmental Quotient (MeDQ) was ( $84.9 \pm 11.01$ vs. $89.4 \pm 13.9 ; p<0.05)$ in "no zinc" and "zinc" group respectively.

Other outcomes:

Zinc group $(n=67)$

Serum zinc (mg/L) before $784.13 \pm 167.90$

after $861.67 \pm 241.5(p=0.013)$

Serum calprotectin $(\mathrm{ng} / \mathrm{ml})$ before $200.87 \pm 87.12$ after $149.43 \pm 77.325$ $(p=0.001)$

Serum IL-6 $(\mathrm{pg} / \mathrm{mL})$ before $68.27 \pm 16.80$ after $51.8 \pm 20.55(p=0.001)$

Serum TNF-a $(\mathrm{pg} / \mathrm{mL})$ before $71.26 \pm 26.8$

after $56.11 \pm 29.65(p=0.001)$

Control group $(n=67)$

Serum zinc (mg/L) before $767.9 \pm 160.9$ after $777.86 \pm 163.2(p=0.59)$

Serum calprotectin $(\mathrm{ng} / \mathrm{mL})$ before $209.25 \pm 88.16$ after $186.9 \pm 92.2(p=0.01)$

Serum IL-6 $(\mathrm{pg} / \mathrm{mL})$ before $62.34 \pm 15.69$ after $55.8 \pm 17.13(p=0.04)$

Serum TNF-a $(\mathrm{pg} / \mathrm{mL})$ before $68.6 \pm 20.7$ after $63.2 \pm 21.09(p=0.10)$

Other outcomes: At one month of age, more number of control group neonates had abnormal neurological findings as compared to the zinc group $[(p=0.02)$; $\mathrm{RR}(95 \% \mathrm{Cl})=0.28(0.11-0.73)] .4 / 42$ vs $14 / 38$.

\begin{tabular}{lll}
\hline Bhatnagar S, & $\begin{array}{l}\text { NICU of three } \\
\text { hospitals, New } \\
\text { Delhi, India }\end{array}$ & $\begin{array}{l}\text { 700 infants aged 7-120 days } \\
\text { in emergency departments } \\
\text { for clinical symptoms or signs } \\
\text { of possible serious bacterial } \\
\text { infection }\end{array}$
\end{tabular}

Study physician gave every infant half a dispersible tablet of zinc ( 5 mg of elemental zinc) or placebo dissolved in $2.5 \mathrm{~mL}$ expressed breastmilk or distilled water orally every $12 \mathrm{~h}$ until recovery in addition to standard antibiotic treatment.

Significantly fewer treatment failures occurred in the zinc group [34] than in the placebo group (55); relative risk reduction $40 \%,(95 \% \mathrm{Cl} 10-60$, $p=0.0113$ ); absolute risk reduction $6.8 \%$, (95\% Cl 1.5-12.0, $p=0.0111)$. Ten infants receiving zinc died compared with 17 given placebo (relative risk $0 \cdot 57,95 \% \mathrm{Cl}$ $0 \cdot 27-1 \cdot 23, p=0 \cdot 15$ ).

Zinc was administered as $3 \mathrm{mg} /$ $\mathrm{kg} / \mathrm{twice}$ a day zinc sulfate monohydrate orally for 15 days along with antibiotics according to a standard protocol. Placebo only received antibiotics and supportive care.
Mortality rate $10 / 100$ in zinc group and $18 / 100$ in placebo group

\begin{tabular}{|c|c|c|c|}
\hline $\begin{array}{l}\text { Elfarargy MS, } \\
2017\end{array}$ & $\begin{array}{l}\text { NICU of Tanta } \\
\text { University Hospital, } \\
\text { Tanta, Egypt }\end{array}$ & $\begin{array}{l}200 \text { Neonates diagnosed with } \\
\text { high probable sepsis } \\
\text { according to criteria } \\
\text { employed for defining the } \\
\text { sepsis score }\end{array}$ & $\begin{array}{l}\text { Zinc was administered as } 3 \mathrm{mg} / \\
\mathrm{kg} / \text { twice a day zinc sulfate } \\
\text { monohydrate orally for } 15 \text { days } \\
\text { along with antibiotics according } \\
\text { to a standard protocol. Placebo } \\
\text { only received antibiotics and } \\
\text { supportive care. }\end{array}$ \\
\hline
\end{tabular}

Preventive and Therapeutic Zinc Supplementation in Young Infant Sepsis
Neonatology 2022;119:164-175

DOI: $10.1159 / 000521275$ 
Table 1 (continued)

\begin{tabular}{|c|c|c|c|c|}
\hline $\begin{array}{l}\text { Elfarargy MS, } \\
2020\end{array}$ & $\begin{array}{l}\text { NICU of Tanta } \\
\text { University Hospital, } \\
\text { Tanta, Egypt }\end{array}$ & $\begin{array}{l}180 \text { preterm neonates } \\
\text { suffering from Neonatal } \\
\text { Sepsis based on Tollner's } \\
\text { sepsis score }\end{array}$ & $\begin{array}{l}\text { Intervention group received } \mathrm{Zn} \\
\text { as } 0.7 \mathrm{~mL} \text { of } \mathrm{Zn} \text { origin/kg/d orally } \\
\text { through oro/ nasogastric tube } \\
\text { divided into two doses (every } 12 \\
\text { h) which is equal to } 1.4 \mathrm{mg} \\
\text { elemental } \mathrm{Zn} / \mathrm{kg} / \mathrm{d} \text { orally for a } \\
\text { period of } 10 \text { days. Control group } \\
\text { received antibiotics according to } \\
\text { standard protocol (ampicillin and } \\
\text { gentamycin) and placebo } \\
\text { (distilled water). }\end{array}$ & $\begin{array}{l}\text { Mortality rate } 2 / 90 \text { in zinc group and } 5 / 90 \\
\text { in placebo group; } \\
\text { Treatment failure } 12 / 90 \text { in zinc group and } \\
20 / 90 \text { in placebo group }\end{array}$ \\
\hline
\end{tabular}

Mehta K, 2013 Pediatric wards of 614 Neonates with probable Zinc at $1 \mathrm{mg} / \mathrm{kg} /$ day dissolved in Institute of Health neonatal sepsis.

Sciences (BPKIHS),

Dharan, Nepal

expressed breastmilk

(formulation: Zinc Sulphate

Dispersible tablets of $10 \mathrm{mg}$ ) either orally or via a nasogastric

tube in neonates kept NPO.

Placebo group received the placebo, in addition to antibiotic

therapy and supportive care.

Ali M, 2020 Outpatient ward at Neonates 3 to 28 days old the Department of with weight between 2.5 to 4 Paediatrics, Sylhet kg. Neonates presenting with M A G Osmani any one or more of the Medical College, following criteria plus positive Sylhet, Bangladesh blood culture report and/or CRP $>10 \mathrm{u} / \mathrm{L}$ : (1) not feeding well, (2) convulsions, (3) fast breathing ( $\geq 60$ breaths/min), (4) severe chest In-drawing, (5) low body temperature (less than $35.5^{\circ} \mathrm{C}$ or $\left.95.9^{\circ} \mathrm{F}\right)$, (6) fever (more than $37.5^{\circ} \mathrm{C}$ or $\left.99.5^{\circ} \mathrm{F}\right),(7)$ movement only when stimulated or no movement at all and neonates with other problems
Neonates were divided into 2 groups: Group A and Group B. Zinc or placebo were prepared in identical packet. Each packet contained $5 \mathrm{mg}$ dispersible zinc sulphate or placebo, given for 7 days. Both groups were given antibiotics and supportive care.
Mortality; zinc 30/307, control 24/307, Use of 2/3 line antibiotics; zinc 41/307, control 37/307, hospital stay (hours); zinc 142.85 (69.41), control 147.99 (73.13).

Clinical recovery [n (\%)] zinc 61 (93.8) vs. control 59 (92.1), Treatment failure $[n(\%)]$ zinc 4 (6.2) vs. control 5 (7.8)

Preventive Zinc supplementation studies

Habib M, 2015 Rural district of Hala Healthy newborns aged and Matiari located between $0-14$ days were about $200 \mathrm{~km} \quad$ enrolled into the study. north-east of Infants beyond this age or Karachi, Pakistan. preterm infants ( $<37$ weeks gestation or $<2 \mathrm{~kg}$ birth weight) or having any major congenital abnormalities were excluded.

Mathur NB, Neonatal unit of a Participants were 100 2015 teaching hospital in consecutively admitted New Delhi, India. preterm neonates $<7$ days old at admission.
Subjects were assigned to either receive $10 \mathrm{mg}$ of zinc or placebo supplementation daily for 18 weeks. Both groups received OPV doses at birth, at 6 weeks, 10 weeks and 14 weeks.
Both zinc and placebo groups reported no cases of bacterial sepsis and mortality.
Neonates were randomized either to receive zinc gluconate ( $2 \mathrm{mg} / \mathrm{kg} /$ day of elemental zinc) or no zinc using website generated random allocation sequence.
Incidence of sepsis [n (\%)] zinc 3 (8.1) vs. control 5 (14.3), Mortality after 3 months follow up $[n(\%)]$ zinc 1 (2.7) vs. control 4 (11.4) 
Table 1 (continued)

\begin{tabular}{|c|c|c|c|c|}
\hline $\begin{array}{l}\text { Study name } \\
\text { and Year }\end{array}$ & $\begin{array}{l}\text { Study setting, City, } \\
\text { Country }\end{array}$ & Participants & Interventions & Outcomes \\
\hline Terrin G, 2013 & $\begin{array}{l}\text { NICU of a hospital, } \\
\text { Turin, Italy }\end{array}$ & $\begin{array}{l}193 \text { Very-low-birth-weight } \\
\text { (VLBW) neonates (birth } \\
\text { weight: } 401-1,500 \mathrm{~g} \text { or a } \\
\text { gestational age of } 24-32 \\
\text { weeks), consecutively } \\
\text { observed in a neonatal } \\
\text { intensive care unit }\end{array}$ & $\begin{array}{l}\text { Commercially available } \\
\text { multivitamin product in drops } \\
\text { containing zinc (Pre-vitamin 0; } \\
\text { DUPI). Placebo control group } \\
\text { received a similar multivitamin } \\
\text { preparation without zinc. }\end{array}$ & $\begin{array}{l}\text { Late-onset sepsis [n (\%)] zinc16 (16.5) vs } \\
\text { control } 12(12.5) p=0.431 \\
\text { Necrotizing enterocolitis [n (\%)] zinc } 0 \text { (0) } \\
\text { vs control } 6(6.3) p=0.014 \\
\text { Bronchopulmonary dysplasia [n (\%)] zinc } \\
10(10.3) \text { vs control } 15(15.6) p=0.272 \\
\text { Periventricular leucomalacia [n (\%)] zinc } 3 \\
\text { (3.1) vs control } 9(9.4) p=0.071 \\
\text { Retinopathy of prematurity zinc } 0(0.0) \text { vs } \\
\text { control } 3 \text { (3.17) } p=0.121\end{array}$ \\
\hline
\end{tabular}

Pooled effect estimates were calculated for mean difference (MD) with 95\% CIs for continuous variables and risk ratio (RR) with 95\% CIs for dichotomous variables using Review Manager version 5.4.1, adopting a random-effects model. An $I^{2}$ of greater than $50 \%$ represents significant heterogeneity. A $p$ value of less than 0.05 in 2-tailed tests indicates statistical significance.

Analysis of Subgroups or Subsets

We performed subgroup analyses where there were at least 3 studies for each subgroup identified, in accordance with Cochrane Collaboration recommendations. Neonatal studies were classified into preventive and therapeutic intervention studies. Further subgroup analyses were conducted for Zinc dosage and duration in young infants.

Risk of Bias (Quality) Assessment

Two review authors independently and in duplicate assessed the risk of bias of included studies using the Cochrane Collaboration Risk of Bias tool [22]. The risk of bias was either rated "high," "low," or "unclear."

\section{GRADE Analysis}

We constructed GRADE Evidence profiles summarizing the certainty of evidence according to the outcomes as per the Grading of Recommendations, Assessment, Development, and Evaluation (GRADE) criteria [23]. It covers consideration of the within-study risk of bias, directness of evidence, heterogeneity, the precision of effect estimates, and the risk of publication bias. We rated the certainty of the evidence for each key outcome as "high," "moderate," "low," or "very low."

\section{Results}

\section{Study Selection}

The search exercise yielded a total of 913 records from the aforementioned databases. After removal of duplicates and the initial title and abstract screening, 10 studies underwent full-text screening. After full-text screening and inclusion of one article from other resources, 11
RCTs $[18,19,24-32]$ were finally included in the review. Two studies $[18,19]$ were excluded from full text review as they were substudies of an already included trial [24]. These two studies have also been previously inaccurately reported [17] as separate studies. We directly approached the study authors to confirm full recruitment and outcome numbers. The search identified 3 ongoing trials [33-35]. The PRISMA flow diagram for study selection is as shown in Figure 1. The included studies were published between 2012 and 2020. Three studies were conducted in India, 2 in Egypt, and one each in Nepal, Pakistan, Bangladesh, and Italy. The study settings included pediatric inpatient wards $[25,27,29,30]$, neonatal ICUs $[24,26,28,32]$, and the community [31]. The characteristics of included studies are as shown in Table 1. The minimum sample size reported was 72 children [30] and the maximum population size was 700 children [25]. Six $[24-27,29,32]$ of the included studies reported the therapeutic effect of zinc supplementation, whereas only 3 studies $[28,30,31]$ evaluated the preventive efficacy of the zinc supplement. We report below the preventive and therapeutic effects of zinc supplementation in neonates and young infants, respectively.

\section{Risk of Bias (Quality) Assessment}

Six out of 9 studies were assessed to be of good quality with a low risk of bias across most of the domains as summarized in online supplementary Figure 1. Mathur and Agarwal [30] reported a high risk of bias in blinding of participants, personnel, and outcome assessment. One study [26] had an unclear risk of bias for sequence generation, allocation concealment, and blinding. Elfarargy et al. [32] adopted a high-risk randomization method for the study trial. 


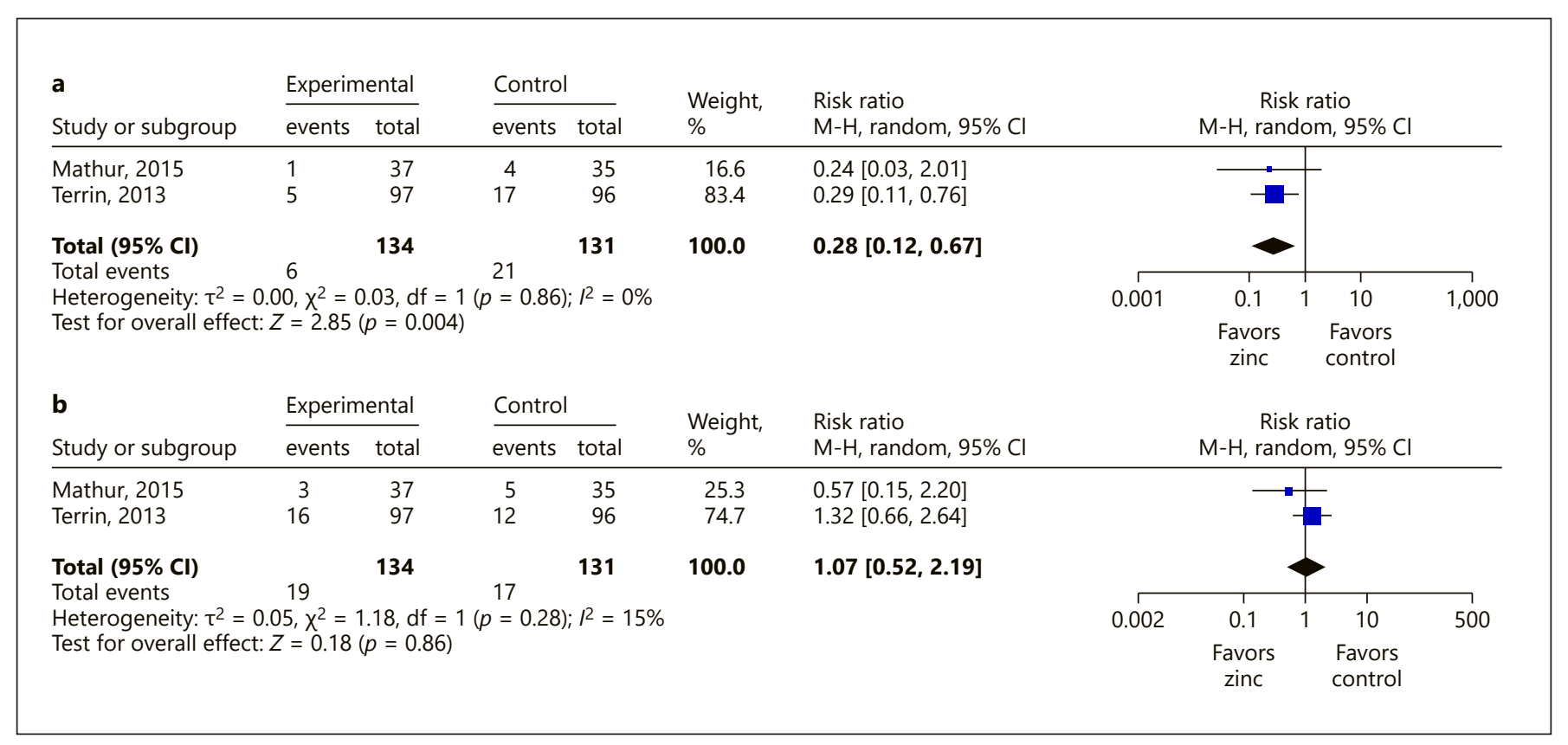

Fig. 2. a, b Effect of preventive zinc supplementation in preterm neonates on mortality and incidence of bacterial sepsis.

\section{Preventive Efficacy of Zinc Supplementation on} Neonatal and Infant Sepsis

Three studies reported the preventive efficacy of zinc supplementation in preterm neonates $[28,30,31]$. GRADE assessment of primary outcomes is as shown in online supplementary Table 1 . Two trials from LMICs, given in mixed inpatient and intensive care settings, reported zinc supplementation to observe significantly lower mortality (RR 0.28; 95\% CI 0.12-0.67; 2 studies; 265 participants; heterogeneity: $\chi^{2} p$ value $0.86 ; I^{2} 0 \%$; LOW certainty on GRADE), but a comparable incidence rate of bacterial sepsis (RR 1.07, 95\% CI 0.52-2.19; 2 studies; 193 participants; heterogeneity: $\chi^{2} p$ value $0.28 ; I^{2} 15 \%$; LOW certainty on GRADE) in preterm neonates, as shown in Figure 2. Both the trials administered zinc supplementation from the 7 th day of life until discharge or 3 months corrected age. Habib et al. [31] reported no occurrence of mortality or cases of bacterial sepsis in their 18 weeks follow-up period in a community study assessing the effect of daily zinc supplement in term infants on oral polio vaccine response.

\section{Therapeutic Efficacy of Zinc Supplementation in \\ Neonatal and Young Infant Sepsis}

A total of 6 trials $[24-27,29,32]$ reported the therapeutic effect of zinc supplementation on proven sepsis in infants up to 4 months of age, all in LMICs. Four studies were conducted in infants admitted to intensive care with sepsis whereas 2 studies recruited infants from inpatient facilities. Bhatnagar et al. [25], reported the protective effect of zinc supplementation compared to placebo with lower need to change antibiotic regimen or ICU admission. Compared with the control group, zinc supplementation showed a comparable decrease in all-cause mortality rate as shown in Figure 3. Mortality rate was further subgrouped according to zinc dosage; dose of $1 \mathrm{mg} / \mathrm{kg} /$ twice a day (RR 0.92, 95\% CI 0.34-2.48, 2 studies; 794 participants; heterogeneity: $\chi^{2} p$ value $0.19 ; I^{2} 43 \%$; LOW certainty on GRADE), dose of $3 \mathrm{mg} / \mathrm{kg} /$ twice a day (RR 0.49 , 95\% CI 0.27-0.87; 2 studies; 350 participants; heterogeneity: $\chi^{2} p$ value $0.55 ; I^{2} 0 \%$; LOW certainty on GRADE), and dose of $5 \mathrm{mg} / \mathrm{kg} /$ twice a day (RR 0.57, 95\% CI 0.27-1.23; one study; 655 participants; MODERATE certainty on GRADE). On further disaggregation of studies, only 3 studies reported the effect of duration of zinc treatment on mortality rate in young infants as shown in Figure 4; 10 days of treatment (RR 0.39, 95\% CI 0.17-0.90; 2 studies; 330 participants; heterogeneity: $\chi^{2} p$ value $0.97 ; I^{2} 0 \%$; LOW certainty on GRADE) and 15 days of treatment (RR 0.56, 95\% CI 0.27-1.14; one study; 228 participants; LOW certainty on GRADE). Zinc supplementation was associated with a significantly lower treatment failure rate (RR $0.61,95 \%$ CI 0.44-0.85; 3 studies; 964 participants; heterogeneity: $\chi^{2} p$ value $0.92 ; I^{2} 0 \%$; MODERATE certainty on GRADE), and insignificant mean hospital stay (MD -4.85 


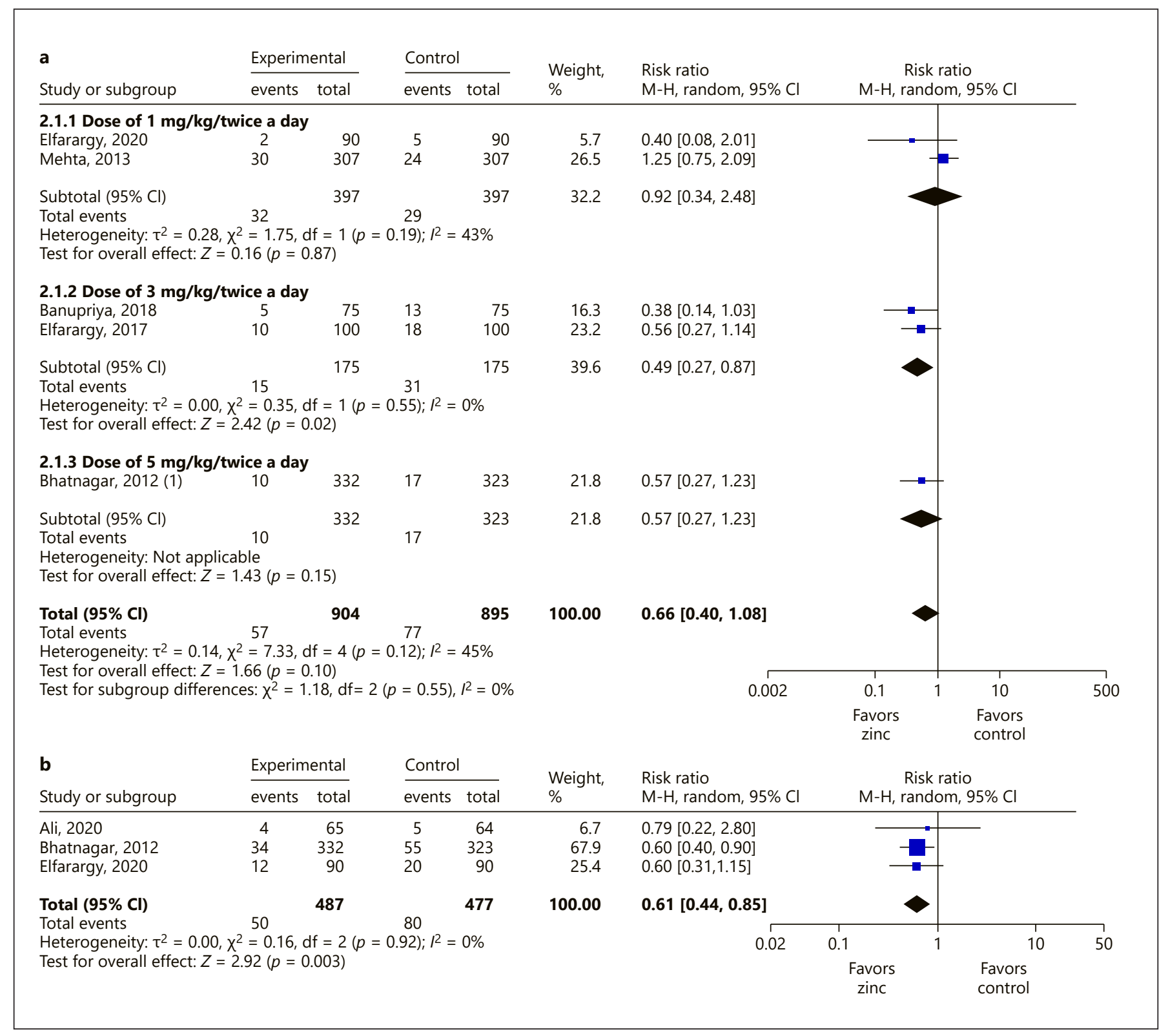

Fig. 3. a, b Effect of therapeutic zinc supplementation in young infants on mortality and treatment failure.

CI -15.08 and $6.11 ; 2$ studies; 748 participants; heterogeneity: $\chi^{2} p$ value $0.83 ; I^{2} 0 \%$; HIGH certainty on GRADE). Banupriya et al. [24], also reported improved Motor Development Quotient (MD 1.44, 95\% CI -4.15 to 7.03) and Mental Development Quotient (MD 4.50, 95\% CI 0.498.51) on 12-month follow-up with zinc supplementation.

Subgroup analysis on the 4 neonatal trials did not show any significant benefit on hospital stay or survival (Fig. 5). Significant improvement in serum zinc concentrations and neurological findings were observed in one trial. Neurological assessments included motor and mental development quotients, any abnormalities in posture, movements, visual or auditory orientation, and behavior.

\section{Discussion and Conclusion}

This is the first review to evaluate the effectiveness of zinc supplementation in young infants. This review includes 9 RCTs, of which ten studies were reported from 


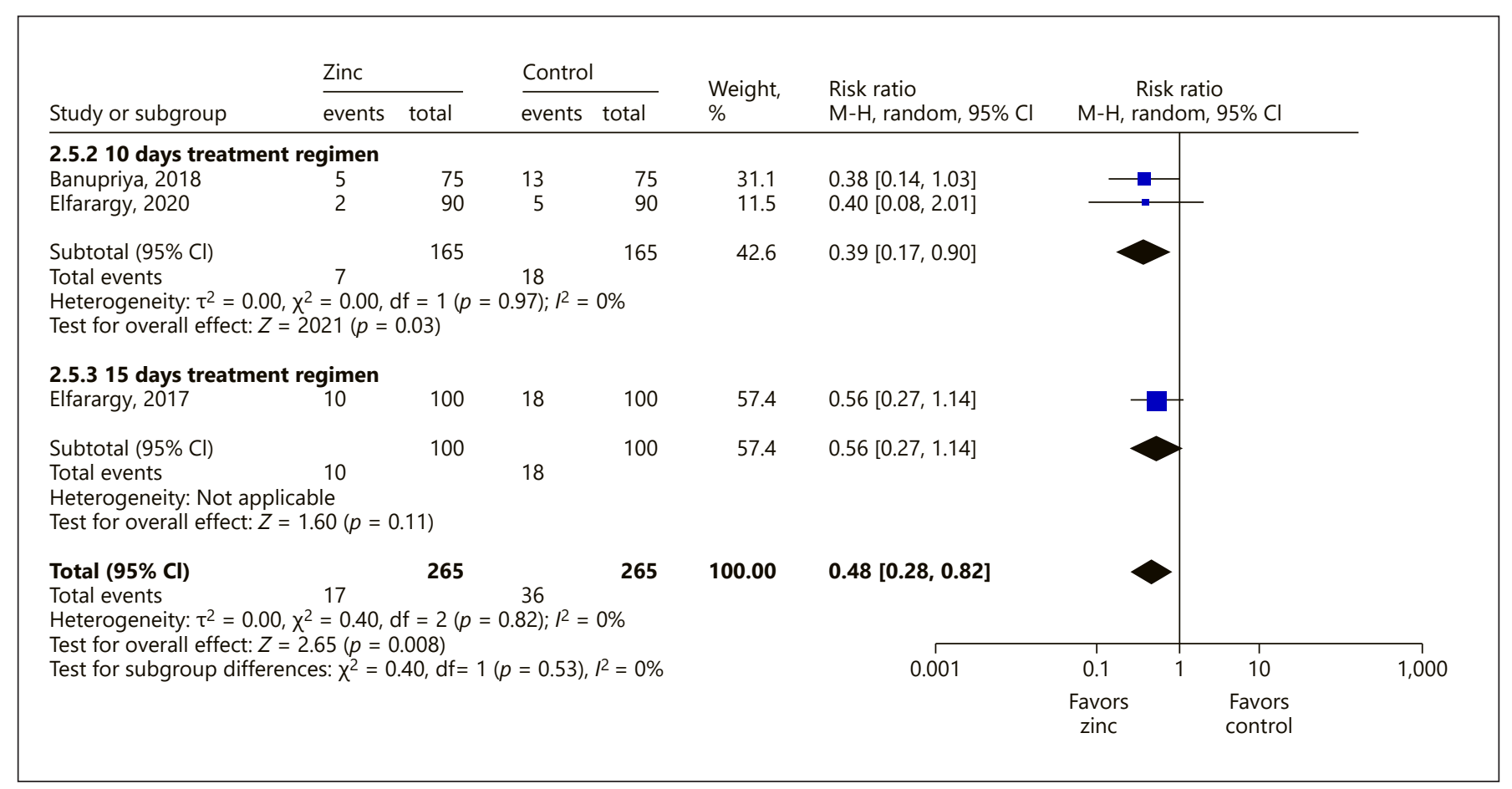

Fig. 4. Effect of duration of therapeutic zinc supplementation in young infants on mortality rate.

the LMICs. Six studies were conducted among infants $(<4$ months) admitted to intensive care, 2 studies from inpatient facilities, whereas one study was a community-based intervention trial. Our meta-analysis of eight RCTs finds that adjunct treatment of young infant sepsis with a $3 \mathrm{mg} /$ $\mathrm{kg} / \mathrm{twice}$ a day dose of zinc supplementation in addition to antibiotics and supportive care, significantly reduces mortality, but not in studies limited to neonatal sepsis $(<1$ month). Furthermore, preventive zinc supplementation reported a lower mortality rate in preterm neonates. Six out of 9 included studies were of good quality with computer-generated randomization, concealed allocation, triple-blinding, minimal attrition, and no other biases reported. The findings of this review are to be cautiously interpreted, with the limited number of studies of small sample sizes included and most of the outcomes were rates low to moderate on GRADE certainty assessment. Due to the low number of included studies, we were unable to perform an assessment of publication bias. Ideally, the comparison of effective dose should be with different doses within the same study rather than among different studies. Furthermore, the studies reported different short durations of zinc supplementation, which makes it important to conduct studies with a long duration of intervention and follow-ups.
Eight studies were reported from the LMICs. The only study from HIC in our cohort was reported from verylow birth weight neonates admitted to the NICU. Zinc deficiency and undernutrition remain a major public health concern in the LMICs [36], where a combination of poor sanitation and hygiene, overcrowding, air pollution, high prevalence of low birth weight deliveries, food insecurity, and inadequate and unstable immunization predispose to increased risk of infection. It is important to formulate large-scale intervention frameworks and identify the most effective strategies to deliver low-cost interventions in LMICs for the population in need [37]. Zinc, which is a low-cost intervention with a good safety profile in the form of supplementation and fortification, is an important micronutrient to be added to existing infant and young child health and nutrition programs [9]. Furthermore, preterm neonates are more predisposed to zinc deficiency. The 2 included studies on preventive zinc supplementation in preterm neonates show an improved mortality rate. Having missed out on an important phase of transplacental nutrient transfer during the third trimester of pregnancy, preterm neonates require adequate intake of macronutrients and micronutrients for growth and rapidly developing organ systems. Preterm infants are less efficient in absorbing zinc from the 


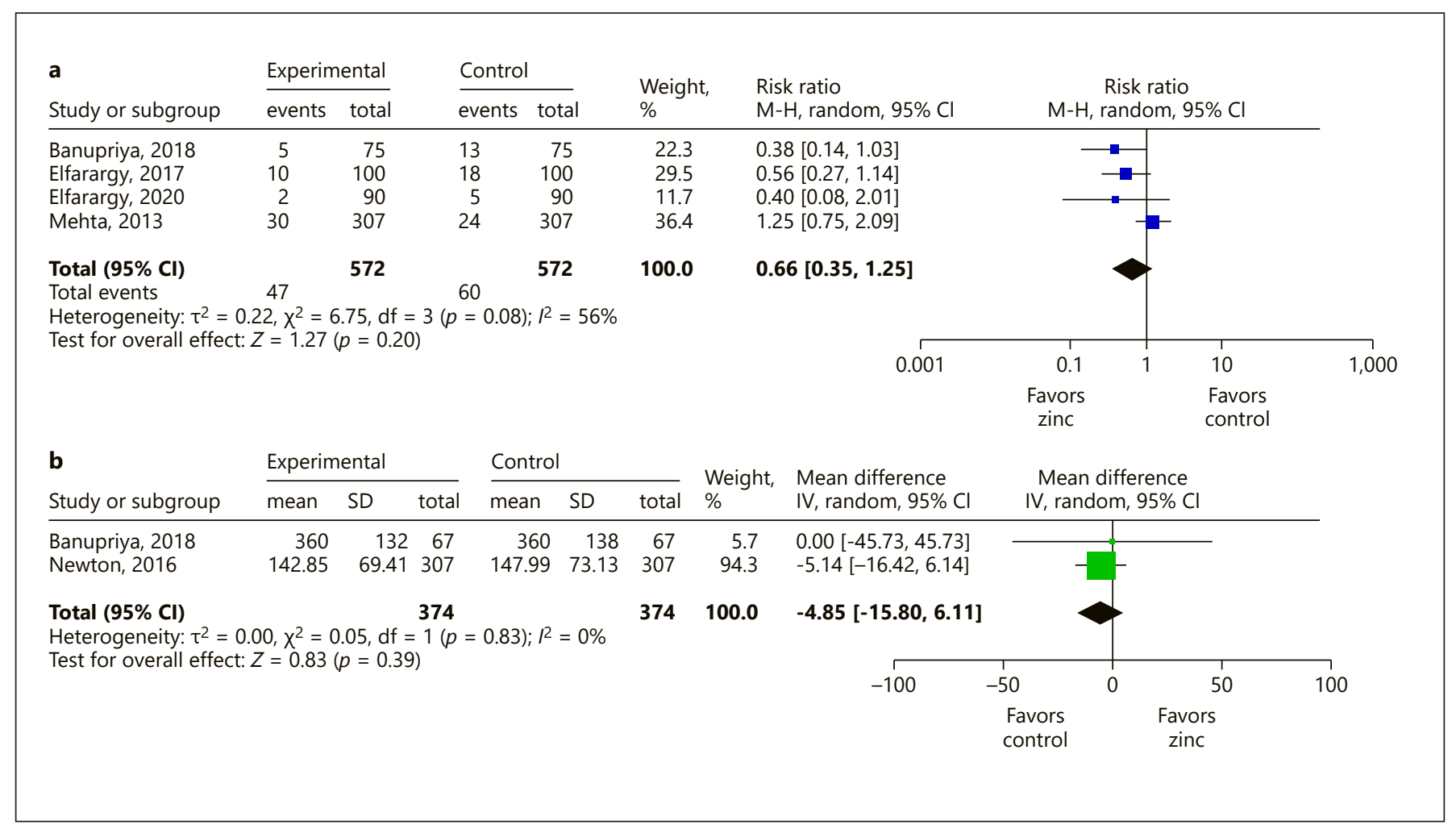

Fig. 5. a-c Effect of therapeutic zinc supplementation in neonates on mortality, serum zinc concentration and hospital stay.

GI tract [38], therefore, they may benefit from higher intake compared to full term neonates to improve growth and reducing the risk of morbidities prevalent in preterm infants.

Most published reviews have assessed the effectiveness of zinc for the prevention or treatment of common childhood diseases including pneumonia and diarrhea and those in older infants and preschool children [39, 40]. There is a paucity of evidence on the efficacy of zinc as a preventive and therapeutic agent in sepsis covering the neonatal and young infant age group. A previous review of 4 RCTs by Tang et al. [17], in neonates reported a significant reduction in neonatal mortality rate and improvement in serum zinc levels in neonatal sepsis, but on further detailed review of the included studies, there was substantial overlapping of subjects despite different study periods. Furthermore, the review reported mortality and expired patients as separate outcomes with an overlap of effects sizes. Another recent review by Smucker et al. [41], narratively synthesized evidence from 3 RCTs, described inconclusive evidence on zinc supplementation as an effective therapy in reducing mortality in neonatal sepsis. A recently published Cochrane review of 2 trials, reports

Preventive and Therapeutic Zinc

Supplementation in Young Infant Sepsis a comparable incidence risk of bacterial sepsis in neonates administered preventive zinc supplementation compared to placebo [21].

RCTs with larger sample sizes are needed in the future to provide conclusive evidence to support the recommendation of zinc as an adjunct therapy to standard care for clinically severe sepsis in young infants. The literature searched yielded a large ongoing trial, underway in India and Nepal, assessing the adjunct treatment benefit of zinc for reducing case-related mortality due to severe bacterial infection in young infants (3-60 days old) [33]. Additional RCTs are also needed to determine if zinc supplementation to pregnant women and/or young infants would prevent the incidence of sepsis and any related mortality. Further trials assessing the effects of zinc supplementation on brain development are needed as zinc deficiency can increase the risk of neurological abnormalities during infancy and adolescence [42]. One included trial reported significant improvement in neurological findings in neonates with sepsis [24]. Although the early period of 1 month of age is too early to detect any definitive neurological abnormality, the findings can have implications for future studies. 
Therapeutic zinc supplementation during sepsis may significantly reduce treatment failure in young infants ( $<4$ months) and potentially reduce mortality rate in the same age group at $3 \mathrm{mg} / \mathrm{kg} /$ day dosage, although this finding must be treated with caution. Studies with larger sample sizes are needed to provide conclusive evidence to support the recommendation of zinc for prevention or treatment for clinically severe sepsis in young infants.

\section{Acknowledgments}

The authors have no contributions to acknowledge for this review.

\section{Statement of Ethics}

The paper is exempt from the Ethical Committee approval because this study is based exclusively on published literature.

\section{Funding Sources}

No funding has been received for this study.

\section{Author Contributions}

Zulfiqar A. Bhutta conceptualized the study. Robert E. Black and Omar Irfan drafted the study protocol; conducted the literature search, study screening, selection, and data extraction; and drafted the manuscript. Omar Irfan drafted the initial manuscript and reviewed and revised the manuscript. Zohra S. Lassi performed the GRADE analysis and reviewed the manuscript. Zulfiqar A. Bhutta and Robert E. Black critically reviewed the manuscript for important intellectual content and approved the final manuscript as submitted. Zulfiqar A. Bhutta is the guarantor.

\section{Data Availability Statement}

All data generated or analyzed during this study are included in this article and its online supplementary material files. Further inquiries can be directed to the corresponding author.

\section{Conflict of Interest Statement}

The authors have no conflicts of interest to declare.

\section{References}

1 Seale AC, Blencowe $\mathrm{H}$, Manu AA, Nair $\mathrm{H}$, Bahl R, Qazi SA, et al. Estimates of possible severe bacterial infection in neonates in subSaharan Africa, south Asia, and Latin America for 2012: a systematic review and meta-analysis. Lancet Infect Dis. 2014;14(8):731-41.

2 Rudd KE, Johnson SC, Agesa KM, Shackelford KA, Tsoi D, Kievlan DR, et al. Global, regional, and national sepsis incidence and mortality, 1990-2017: analysis for the Global Burden of Disease Study. Lancet. 2020; 395(10219):200-11.

3 Bakhuizen SE, De Haan TR, Teune MJ, van Wassenaer-Leemhuis AG, Van Der Heyden JL, Van Der Ham DP, et al. Meta-analysis shows that infants who have suffered neonatal sepsis face an increased risk of mortality and severe complications. Acta Paediatrica. 2014; 103(12):1211-8.

4 Stoll BJ, Hansen NI, Sánchez PJ, Faix RG, Poindexter BB, Van Meurs KP, et al. Early onset neonatal sepsis: the burden of group $B$ Streptococcal and E. coli disease continues. Pediatrics. 2011;127(5):817-26.

5 Naher BS, Mannan MA, Noor K, Shahiddullah M. Role of serum procalcitonin and C-reactive protein in the diagnosis of neonatal sepsis. Bangladesh Med Res Counc Bull. 2011; 37(2):40-6.
6 Leal YA, Álvarez-Nemegyei J, Velázquez JR, Rosado-Quiab U, Diego-Rodríguez N, PazBaeza E, et al. Risk factors and prognosis for neonatal sepsis in southeastern Mexico: analysis of a four-year historic cohort follow-up. BMC Pregnancy Childbirth. 2012;12(1):48.

7 National Institute for Health and Care Excellence. Neonatal infection (early onset): antibiotics for prevention and treatment. 2014. Available from: https://wwwniceorguk/guidance/cg149/evidence/evidence-updatepdf-188168797.

8 Hutubessy RC, Baltussen R, Torres-Edejer T, Evans D. WHO-CHOICE: choosing interventions that are cost-effective. In: Health systems performance assessment: debates, methods and empiricism. Geneva: WHO; 2003. p. 823-35.

9 Roohani N, Hurrell R, Kelishadi R, Schulin R. Zinc and its importance for human health: an integrative review. J Res Med Sci. 2013;18(2): 144.

10 Jarosz M, Olbert M, Wyszogrodzka G, Młyniec K, Librowski T. Antioxidant and anti-inflammatory effects of zinc. Zinc-dependent NF- $\kappa \mathrm{B}$ signaling. Inflammopharmacology. 2017;25(1):11-24.
11 Wang L, Song Y. Efficacy of zinc given as an adjunct to the treatment of severe pneumonia: a meta-analysis of randomized, doubleblind and placebo-controlled trials. Clin Respir J. 2018;12(3):857-64.

12 Chaffee BW, King JC. Effect of zinc supplementation on pregnancy and infant outcomes: a systematic review. Paediatr Perinat Epidemiol. 2012;26 Suppl 1:118-37.

13 Ramakrishnan U. Nutrition and low birth weight: from research to practice. Am J Clin Nutr. 2004;79(1):17-21.

14 WHO. Zinc supplementation in the management of diarrhoea [Internet]. 2016 [cited 2021 Jun 22]. Available from: https://www.who. int/elena/titles/bbc/zinc_diarrhoea/en/.

15 Walker C, Bhutta Z, Bhandari N, Teka T, Shahid F, Taneja S, et al. Zinc supplementation for the treatment of diarrhea in infants in Pakistan, India and Ethiopia. J Pediatr Gastroenterol Nutr. 2006;43(3):357-63.

16 Banupriya N, Bhat BV, Vickneshwaran V, Sridhar MG. Effect of zinc supplementation on relative expression of immune response genes in neonates with sepsis: a preliminary study. Indian J Med Res. 2020;152(3):296.

17 Tang Z, Wei Z, Wen F, Wu Y. Efficacy of zinc supplementation for neonatal sepsis: a systematic review and meta-analysis. J Matern Fetal Neonatal Med. 2019;32(7):1213-8. 
18 Newton B, Bhat BV, Dhas BB, Mondal N, Gopalakrishna SM. Effect of zinc supplementation on early outcome of neonatal sepsis: a randomized controlled trial. Indian J Pediatr. 2016;83(4):289-93.

19 Banupriya N, Vishnu Bhat B, Benet BD, Sridhar MG, Parija SC. Efficacy of zinc supplementation on serum calprotectin, inflammatory cytokines and outcome in neonatal sepsis: a randomized controlled trial. J Matern Fetal Neonatal Med. 2017;30(13):1627-31.

20 Schüller SS, Kramer BW, Villamor E, Spittler A, Berger A, Levy O. Immunomodulation to prevent or treat neonatal sepsis: past, present, and future. Front Pediatr. 2018;6:199.

21 Staub E, Evers K, Askie LM. Enteral zinc supplementation for prevention of morbidity and mortality in preterm neonates. Cochrane Database Syst Rev. 2021 Mar 12;3(3):CD012797.

22 Higgins JP, Altman DG, Gøtzsche PC, Jüni P, Moher D, Oxman AD, et al. The Cochrane Collaboration's tool for assessing risk of bias in randomised trials. BMJ. 2011;343:d5928.

23 Guyatt G, Oxman AD, Akl EA, Kunz R, Vist G, Brozek J, et al. GRADE guidelines: 1. Introduction: GRADE evidence profiles and summary of findings tables. J Clin Epidemiol. 2011;64(4):383-94.

24 Banupriya N, Bhat BV, Benet BD, Catherine C, Sridhar MG, Parija SC. Short term oral zinc supplementation among babies with neonatal sepsis for reducing mortality and improving outcome: a double-blind randomized controlled trial. Indian J Pediatr. 2018;85(1):5-9.

25 Bhatnagar S, Wadhwa N, Aneja S, Lodha R, Kabra SK, Natchu UCM, et al. Zinc as adjunct treatment in infants aged between 7 and 120 days with probable serious bacterial infection: a randomised, double-blind, placebo-controlled trial. Lancet. 2012;379(9831):2072-8.

26 El Frargy MS, Soliman NA. Zinc supplementation as an adjuvant treatment in neonatal sepsis. Curr Pediatr Res. 2017;21(1):93-8.
27 Mehta K, Bhatta NK, Majhi S, Shrivastava MK, Singh RR. Oral zinc supplementation for reducing mortality in probable neonatal sepsis: a double blind randomized placebo controlled trial. Indian Pediatr. 2013;50(4):390-3.

28 Terrin G, Berni Canani R, Passariello A, Messina F, Conti MG, Caoci S, et al. Zinc supplementation reduces morbidity and mortality in very-low-birth-weight preterm neonates: a hospital-based randomized, placebo-controlled trial in an industrialized country. Am J Clin Nutr. 2013;98(6):1468-74.

29 Ali SM, Hoque M, Ali M, Talukder NU, Chowdhury T. Zinc as adjunct therapy in neonatal sepsis. Med Today. 2020;32(2):1126.

30 Mathur NB, Agarwal DK. Zinc supplementation in preterm neonates and neurological development: a randomized controlled trial. Indian Pediatr. 2015;52(11):951-5.

31 Habib M, Soofi S, Sheraz A, Bhatti Z, Okayasu $\mathrm{H}$, Zaidi S, et al. Zinc supplementation fails to increase the immunogenicity of oral poliovirus vaccine: a randomized controlled trial. Vaccine. 2015;33(6):819-25

32 Elfarargy MS, Al-Ashmawy G, Abu-Risha S, Khattab H. Zinc supplementation in preterm neonates with late-onset sepsis: is it beneficial? Am J Perinatol. 2020 Dec 7. Epub ahead of print.

33 Wadhwa N, Basnet S, Natchu UCM, Shrestha LP, Bhatnagar S, Sommerfelt $\mathrm{H}$, et al. Zinc as an adjunct treatment for reducing case fatality due to clinical severe infection in young infants: study protocol for a randomized controlled trial. BMC Pharmacol Toxicol. 2017; 18(1):1-10.
34 Choopani R. The effect of oral zinc on reduction of mortality in newborns with neonatal sepsis. IRCT20180915041040N2. IRCT. 2019. Available from: https://en.irct.ir/trial/35196.

35 Kaban R, Azis H. Zinc supplementation on very low birth weight infant. ClinicalTrials. gov. NCT04050488. 2019. Available from: https: //clinicaltrials.gov/ct2/show/ NCT04050488.

36 Gupta S, Brazier A, Lowe N. Zinc deficiency in low and middle income countries: prevalence and approaches for mitigation. J Hum Nutr Diet. 2020;33(5):624-43.

37 Wazny K, Zipursky A, Black R, Curtis V, Duggan $C$, Guerrant R, et al. Setting research priorities to reduce mortality and morbidity of childhood diarrhoeal disease in the next 15 years. PLoS Med. 2013;10(5):e1001446.

38 King JC, Shames DM, Woodhouse LR. Zinc homeostasis in humans. J Nutr. 2000;130(5): 1360S-6S.

39 Lassi ZS, Moin A, Bhutta ZA. Zinc supplementation for the prevention of pneumonia in children aged 2 months to 59 months. Cochrane Database Syst Rev. 2016;12(12): CD005978.

40 Fu W, Ding LR, Zhuang C, Zhou YH. Effects of zinc supplementation on the incidence of mortality in preschool children: a meta-analysis of randomized controlled trials. PLoS One. 2013;8(11):e79998.

41 Smucker AR. "Is oral zinc supplementation effective in reducing mortality rate in neonatal sepsis?" PCOM Physician Assistant Studies Student Scholarship. 2020. 533. Available from: https://digitalcommons.pcom.edu/pa systematic_reviews/533.

42 Black MM. Zinc deficiency and child development. Am J Clin Nutr. 1998;68(2):464S-9S.

43 Villamor-Martinez E, Villamor E. Efficacy of enteral zinc supplementation for neonatal sepsis. J Matern Fetal Neonatal Med. 2020 Sep;33(18):3207-8. 